\title{
A Pilot study of the Online Assessment of Self-Regulated Learning in Preschool Children: Development of a Direct, Quantitative Measurement Tool
}

\begin{tabular}{ll}
\hline Received: & 24 September 2019 \\
Revised: $\quad 13$ November 2019 \\
Accepted: $\quad 20$ November 2019 \\
ISSN: 1307-9298 \\
Copyright @ IEJEE \\
www.iejee.com
\end{tabular}

\author{
Lisa Jacoba, ${ }^{a}$, Sandra Dörrenbächer ${ }^{b}$, Franziska Perelsc
}

DOI: 10.26822/iejee.2019257655

\begin{abstract}
Self-regulatory abilities have been shown to be closely linked to academic success. There are a variety of measurement tools to assess self-regulated learning in pupils and students. Crucially, preschool age marks a sensible period for the maturation of self-regulated learning (SRL) and related abilities such as executive-control functions (EF). This is why the development of a direct instrument that fits the special characteristics of this age cohort is important. An adapted version of Zimmermann's (2000) process model may serve as a theoretical basis. This pilot study intends to develop and evaluate a direct, quantitative measurement tool to assess SRL in an 'online manner'. The measurement tool was tested in 183 preschoolers of German kindergartens. After a detailed item analysis, reliability was estimated and concurrent validity was examined. Statistical analysis indicates a satisfactory reliability for the measurement tool as a whole. Additionally, validity is supported by (small) significant overall correlations with the external measure as well as EF measure. Nevertheless, the need for the optimization of the instrument is clear and the study has important implications for further research. In general, the results demonstrate that it is both plausible and possible to assess SRL in preschoolers directly at child level
\end{abstract}

Keywords: Self-Regulated Learning, Preschool Age, Direct Assessment, Executive Functions, Pro-cess Model of Self-Regulated Learning

\section{Introduction}

Self-regulated learning (SRL), that is, the ability to learn through the autonomous and self-directed application of strategies, is crucial for dealing with the fast-moving challenges and demands of everyday life (Brunstein \& Spörer, 2010). Given the undeniable link of such self-regulatory, strategic skills to academic success (e.g. McClelland, Acock, Piccinin, Rhea, \& Stallings, 2013), self-regulated learning has been examined primarily in students (e.g. Dörrenbächer, Russer, \& Perels, 2018, Fadlelmula, Cakiroglu, \& Sungur, 2015; Schnell, Ringeisen, Raufelder, \& Rohrmann, 2015) and (under-) graduates (e.g. Mega, Ronconi, \& De Beni, 2014; Tabuenca, Kalz, Drachsler, \& Specht, 2015, Leidinger \& Perels, 2012). However, from a developmental perspective, it seems essential to expand the research focus to earlier stages of the lifespan, too: importantly, preschool age has been shown to mark the sensitive period for the maturation of SRL and closely related abilities, such as the development of executive control functions (EF; Hofmann, Schmeichel, \& Baddeley, 2012; Lockl \& Schneider, 2007; Zelazo, 2015). However, the assessment of SRL, or EF, respectively, in preschool age requires specific measurement tools that match the particular characteristics of this age group (Hoyle \& Dent, 2018), e.g. the restricted reading abilities or limited memory capacity (Van Den Broek, Kendeou, Lousberg, \& Visser, 2011). Kindergarten teacher ratings have become established for these age ranges (Howse, Lange, Farran, \& Boyles, 2003). The sole application of such external ratings has to be been deemed critical due to the missing possibility for countervalidation. There is, however, a lack of instruments that measure SRL directly at the child level. Hence, the aims of the present study are (1) to take the first steps towards the development of an instrument for the direct and quantitative (online-) assessment of SRL in preschoolers at the child level and (2) to evaluate its psychometric quality.

\section{Self-Regulated Learning at Preschool Age}

SRL (precursor) skills at preschool age ('Preschool age' describes the age span between 5 and 6 when German children generally attend their last year of kindergarten) predict SRL abilities in later life (e.g. McClelland et al., 2013), which implies that early limitations in SRL may amplify poor learn-ing control in adulthood. Hence, given the predictive power of SRL competencies for later 'life success', it seems worthwhile to start early in life with the measurement and instruction of stra-tegic, self-regulated activities (Montroy, Bowles, Skibbe, Mcclelland, \& Morrison, 2016). Moreover, considering the high correlations with other fluid intellectual abilities (Brydges, Reid, Fox, \& Anderson, 2012), well-developed SRL (precursor) skills as well as practiced EF may also foster cognitive development in general. Preschool age in particular represents a sen-sitive period for cognitive maturation: there appears to be a general shift from emotion-driven regulation to a more cognitive regulation where complex learning processes like SRL can be built upon (Zelazo, 2015). Moreover, a qualitative shift from an external regulation to a more internally guided self-regulation style can be observed (see Montroy et al., 2016). In this age range, SRL is also closely related to core developmental tasks, such as good habits and adequate peer behaviour (McClelland, Morrison, \& Holmes, 2000). Thus, SRL helps to reduce im-pulsive behaviour and allows for 'thinking before acting'(Eisenberg et al., 2005), both support-ing the development of social appropriateness that may be particularly important in educational settings. In summary, self-regulation (precursor) skills seem to be a hallmark for everyday-functioning in the age group of preschoolers (Bronson, 2000; Kochanska, Coy, \& Murray, 2001).

SRL in general can be defined from two different perspectives: Putting an emphasis on the temporal dimension, SRL is regarded as a dynamic cycle of different learning stages (Zimmerman, 2000). From a structural perspective, SRL is as-

\footnotetext{
a, ${ }^{\star}$ Corresponding Author: Lisa Jacob, Department of Educational Sciences, Saarland University, Saarbrücken. Campus, Building A4 2, Room 4.19, 66123 Saarbrücken, Germany. E-mail: li-sa.jacob@uni-saarland.de

Sandra Dörrenbächer, Department of Educational Sciences, Saarland University, Saarbrücken, Germany. E-mail: sandra.doerrenbacher@uni-saarland.de ' Franziska Perels, Department of Educational Sciences, Saarland University, Saarbrücken, Germany. E-mail: f.perels@mx.uni-saarland.de
} 
sumed to be composed of a set of cognitive, metacognitive and motivational learning strategies that can be applied within this dynamic learning cycle. Regarding the latter structural dimension of SRL, it has to be consid-ered that at preschool age, the cognitive system is still poorly differentiated (Brydges et al., 2012; Shing, Diamond, \& Davidson, 2010), implying that the unity of SRL components or strategies disproportionately may outweigh the diversity of strategies. Consequently, SRL at preschool age may be defined more sharply on the temporal axis than on the structural axis, which should be considered when constructing a measurement tool for preschoolers.

Theoretical Considerations Regarding Self-Regulated Learning in Preschool Age

In the present study, we rely on the social-cognitive framework of SRL by Zimmerman (2000) that emphasizes the temporal, dynamic character of SRL. In this framework, SRL is defined as 'self-generated thoughts, feelings, and actions that are planned and cyclically adapted to the attainment of personal goals' (Zimmerman 2000, p.14). According to Zimmerman (2000), throughout the SRL process, a multitude of strategies can be applied. However, given the primacy of the temporal compared to the structural (strategy-related) dimension of SRL in preschoolers (see previous section), we propose an adapted version of the framework with a focus on the temporal differentiation and a looser, more parsimonious differentiation of SRL strategies within the SRL process than in the Zimmerman model (2000; see figure 1). When selecting relevant SRL strategies, the state of development of children at preschool age was considered: (a) Children of that age group are capable of goal setting and adjustment of thinking and acting towards goals (Blaye \& Chevalier, 2011; Hendry, Jones, \& Charman, 2016), which represent important skills concerning the forethought phase and the performance phase of SRL; (b) Furthermore, preschoolers already show inhibitory control (Carlson, 2005; Lewis, Reeve, Kelly, \& Johnson, 2017), and attention focusing skills (Bronson, 2000; Lewis et al., 2017) which are relevant abilities, especially for the performance phase; (c) preschoolers can reflect their own learning process (Zelazo, 2015) which is essential for the self reflection phase of SRL.

\section{Executive Functioning at Preschool Age}

Preschool age is simultaneously the critical period for the maturation of another class of basic cognitive skills, namely EF such as shifting, updating or inhibition (Erb, Moher, Song, \& Sobel, 2017; Shaul \& Schwartz, 2014). Such EF enable individuals to perform higher level cognitive operations, such as planning, problemsolving and target-oriented acting (Miyake et al., 2000) and can be thus considered comparable to SRL skills (Perry, Hutchinson, Yee, \& Määttä, 2018; see also the next section for a discussion of the relationship of both concepts). For the assessment of EF in preschoolers, in contrast to the assessment of SRL, there already exists a considerable number of quantitative, direct measurement tools (Ackerman \& Friedman-Krauss, 2017). A common instrument to measure higher level EF is the well-established Tower of London Test (ToL Test, Shallice, 1982) that has also been successfully administered to preschoolers (Byrd, Van Der Veen, McNamara, \& Berg, 2004) and has proven to be a useful instrument to capture interindividual differences in children (Raizner, Song, \& Levin, 2002). The ToL Test consists of reconstructing target configurations with the aid of coloured balls by considering a predetermined number of action steps (also see method section).

\section{The Relationship Between Self-Regulated Learning and Executive} Functioning

Higher level EF shows some conceptual overlap with SRL, both having a heterogeneous structure, and encompassing a wide and diffuse range of interrelated, yet unique abilities (Jurado \& Rosselli, 2007; C. C. Ponitz, McClelland, Matthews, \& Morrison, 2009). However, the precise nature of the relationship among both constructs remains elusive so far (e.g. Hofmann, Schmeichel, \& Baddeley, 2012). Some authors argue that SRL can be interchangea-bly with EF (Gaskins, Satlow, Presseey, \& Meltzer, 2007), while some argue that SRL can be considered as a superordinate construct, including executive basis operations (Barkley, 2001). In a recent review by Hofmann et al. (2012), EF has been subdivided into a set of subcompo-nents, including (a) working memory operations, (b) behavioural inhibition and (c) task-switching, that are directly related to a number of self-regulatory mechanisms, such as (a) the active representation of self-regulatory goals, (b) the active inhibition of 'mindless' behaviour, and (c) self-regulatory goal shifting and balancing. Lockl and Schneider (2007) consider the development of $\mathrm{EF}$ as a precondition for the emergence of SRL abilities.

Given the undoubtedly close relationship between both constructs, of whatever nature, and the greater availability of direct measurement tools for higher level EF for preschoolers (such as the ToL test, Shallice, 1982), such EF tasks seem well suited as a criterion, against which a newly developed SRL measure tool needs to prove itself.

\section{Previous Attempts to Measure Self-Regulation In Preschoolers}

There are at least four general challenges associated with the direct measurement of SRL in preschoolers: (a) their restricted reading and writing skills, (b) their fragile memory for past events which may impede retrospective recall of strategy knowledge (Maylor \& Logie, 2010), (c) misjudgements of their own performance (Schneider \& Büttner, 2008), and (d) a low test compliance for standard instructions (Stephenson \& Hanley, 2010).

Previous attempts to measure self-regulation in preschoolers can be classified into two major approaches: offline and online measures (e.g. Winnie \& Perry, 2005). Regarding offline methods that assess SRL before or after a learning activity, structured interviews seem feasible for the special age cohort of preschoolers, yet they need to be applied in child-appropriate ways due to the restricted language proficiency, the low test compliance in preschoolers and the lack of metacognitive abilities that enable them to verbalize their own learning process (Whitebread et al., 2009). A rare example of a successful application of such a structured interview is the study by Perels, Merget-Kullmann, Wende, Schmitz and Buchbinder

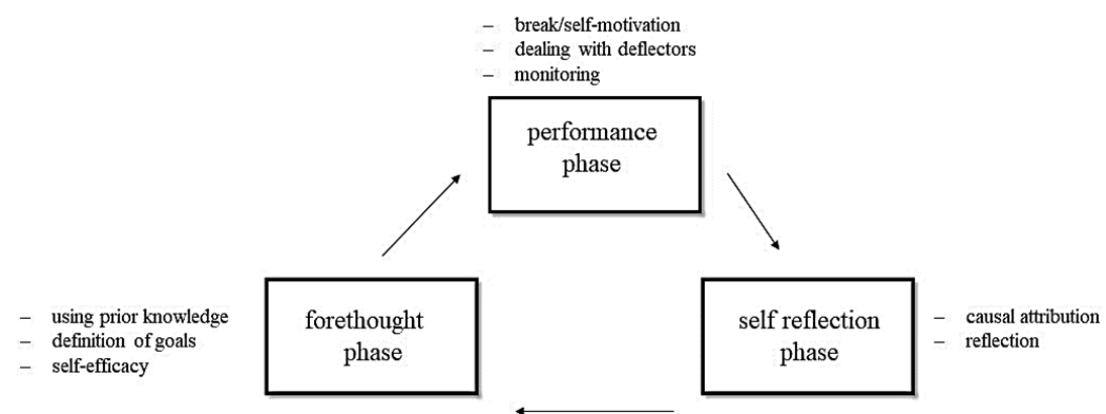

Figure 1. Zimmerman's (2000) process model of SRL, adapted for preschoolers 
(2009). They provided preschoolers with interviews embedded into a puppet show to enhance the children's treatment compliance. However, preschoolers' tendency to overestimate the abilities they are asked about limits the results of the interviews (Schneider \& Büttner, 2008). Another useful measurement method seem to be external assessment as rated by trained kindergarten teachers (Howse et al., 2003). External rating scales that are frequently used include the Child Behavior Rating Scale (Bronson, 1994), the Strengths and Difficulties Questionnaire (Goodman, 1997), or the CHILD-Checklist (Whitebread et al., 2009). However, there is a lack of reliable self-assessment in pre-schoolers to allow for a cross-validation of these indirect measures.

A useful online measure of SRL at preschool age are thinkaloud protocols. It has been shown that four year old children are already capable of articulating their own thoughts when viewing a picture book (Paris \& Paris, 2003; Tompkins, Guo, \& Justice, 2013). However, a relevant disadvantage of thinking aloud methods as a measure of SRL is the high demand on productive language skills and metacognitive skills. Another measurement tool is observational inventories, including the Bronson's Social and Task Skills Profile (Bronson, 1994), the C.Ind.Le Coding Framework (Whitebread et. al., 2009) and the SRL observation tool using the Train Track Task (Bryce \& Whitebread, 2012). However, a disadvantage of behavioural observation is that learning strategies that are known implicitly but not demonstrated during obser-vation may not be captured, thus underestimating children's strategy knowledge (Landmann, Perels, Otto, Schnick-Vollmer, \& Schmitz, 2009).

In the present study, we aimed to develop a measurement tool that counteracts these disadvantages of established instruments. The online character of our tool may limit bias due to the insufficient self-estimation skills of children at that age, allows for direct measurement on child level, requires little productive language skills, captures a set of SRL learning strategies which are considered important for preschoolers, and provides quantitatively interpretable data based on a standardized evaluation protocol. The measurement tool should be evaluable by realizing cross-validation against an external SRL measurement tool and a direct EF measure-ment tool.

The Present Study: Development, Evaluation and Conceptual Alignment of a Direct, Quantitative SRL 'Online' Measurement Tool for Preschoolers

To summarize we aimed to develop an SRL online test procedure for preschoolers that meets the following criteria: First, the temporal SRL dimension should be focused. Second, we aimed to develop a quantitative rather than a qualitative tool to allow for clear interpretability and comparability. Third, the tool should address the children directly (i.e. online measure-ment), thus requiring some adaptions to the particular needs of this age group. Fourth, our tool should be cross-validated against established instruments from a familiar domain of research that already provides adequate quantitative online measurement tools for preschoolers, namely research on EF.

Our developed SRL test procedure was inspired by the direct and quantitative test of metacognition for first graders used in the German National Educational Panel Study that meets most of these criteria (Lockl, Händel, Haberkorn, \& Weinert, 2016). Metacognition (to-gether with cognition and motivation) represents a core component of SRL (Boekarts, 1999) and describes the availability of 'meta-information' about many different types of cognitive processes. Similarly, knowledge about SRL means specific 'meta-information' about learning processes. Lockl et al. (2016) presented groups of first graders orally with twenty child-oriented everyday problem scenarios involving different settings and characters. Each scenario required the selection between three more or less strategic response options to solve the presented problem. This test of metacognition is tailoring towards the particular needs of the age group of first graders may still present some disadvantages for preschool age: First, the test of metacognition only focuses on the metacognitive component of self-regulation, and does not specifically address the temporal, processual character of self-regulated learning that is of primary interest in preschoolers. Second, the asymmetric reply format may allow for error of central tendency, which seems especially harmful in five to six preschoolers with a large degree of decision uncertainty (Hembacher \& Ghetti, 2014). Third, alternating protagonists could lead to excessive demands on preschoolers with regard to their only partially developed ability to grasp perspectives (Gamannossi \& Pinto, 2014). For the development of our instrument, we aimed to adapt the test of metacognition to the specific needs of preschoolers.

\section{Research Questions}

This study examines whether our newly developed SRL measurement tool is a reliable and valid instrument to measure self-regulated learning in preschoolers. It addresses the following research questions:

1. Does the application of a newly developed SRL measurement tool yield data indicating a sufficient reliability when regarding (a) the tool as a whole and (b) three theoretically based subscales (along the timeline of the self-regulated learning process)?

2. Can scores from the newly developed SRL measurement tool be considered valid indicators of preschoolers' SRL abilities when using two kinds of cross-validation strategies, namely (a) 'near cross-validation': comparison with the results of a SRL measurement tool that is rated externally and (b) 'far cross-validation': comparison with the performance in a EF measurement tool that is also applied at child-level?

\section{Method}

\section{Participants}

For this study, 183 preschoolers were recruited from 11 kindergartens in Germany. Nineteen children had to be excluded from the analysis, either because they refused to undergo the testing procedure $(n=17)$ or due to excessive missing data $(n=2)$. Hence, the final sample for analysis consisted of 164 children (51.5 \% male and $47.3 \%$ female; mean age: 5.9 , age range: $4.9-6.7)$. All parents gave their written consent for the participation of their children in the study, in accordance with national law and the protocols approved by the local ethics committee. All children had normal or corrected to normal vision, no hearing impairment and no history of any neurological diseases. Based on parents' statements, none of the children had a known learning disability or suffered from developmental delay.

\section{Procedure and Design}

The testing procedure consisted of two sessions and was conducted in separate, quiet rooms in kindergarten buildings. All tests were conducted by competent test administrators which underwent training sessions and adhered to a standardized test manual. On average, the test session took 18.4 minutes. The relevant instruments were embedded in a series of tasks. The order of task presentation was always the same: At first, the SRL measurement tool for preschoolers was administered; subsequently, children worked on an EF test (Tower of London Test; Shallice, 1982). Each child was tested individually with two administrators present. As a thank you for their participation, children received a child-friendly certificate of attendance after they had completed all tasks. 
An external assessment of preschoolers' SRL ability in the form of a questionnaire was given to the kindergarten teachers at a first informative meeting in the run-up of the testing procedure and recollected at the day of the first testing session.

\section{Measures}

Self-regulated learning in preschoolers (SRL measure tool for preschoolers). The present study applied this newly developed direct and quantitative test tool to investigate SRL in preschool children.

\section{Cover story, structure of measurement tool and items}

The testing script revolves around a background story in which a fictional protagonist called Lennie the Lion is confronted with everyday problems and tries to solve them using various strategies. The story is partly based on the cover story of an earlier study of Perels (2009). Children are instructed to assist Lennie in 'real time' in planning, performing and reflecting a chosen way of proceeding according to a predefined overarching goal (i.e. finding a present for his friend Ellie the duck on the occasion of her first day in school). Hence, the narrative is about different problem scenarios within the story's framework, throughout which the protagonist evolves and develops solution strategies in a step-wise fashion. The measurement tool captures the following SRL strategies: planning, using prior knowledge, dealing with deflectors, self-efficacy, monitoring, breaks and self-motivation, reflection and causal attribution (see figure 1, Zimmerman, 2000). Children are instructed to rate the usefulness of Lennie's proposed solution strategies to master the problem scenarios, similarly to Lockl et al. (2016). Children should rate the usefulness, in a dichotomous response format, as 'not very beneficial' or 'highly beneficial' to the objectives of the protagonist ('Do you think Lennie's idea is a good/bad idea or a bad/ good idea'? in varying order) by tapping a happy or an unhappy face (child oriented display format of response scale). Highly beneficial solution strategies represent one amongst eight SRL strategies (i.e. 'SRL+' items) supposed to be relevant for preschool age (c. figure 1, adapted version of Zimmerman's [2000] process model of SRL). In contrast, less beneficial solution strategies represent non-SRL strategies (i.e. 'SRL- 'items). The number of SRL (+) and SRL (-) was counterbalanced across the test procedure, and items were presented in randomized order. An example problem scenario for the SRL strategy planning (forethought phase) with two corresponding items is shown in Figure 2. Further example problem scenarios can be found in appendix A.

In sum, the measurement tool consists of 24 items. A total score was calculated by following the signal detection theory (Swets, 1996): +1 point for hits [Hits= Child taps happy face in
SRL (+) item] and corrects rejections [Correct rejections= Child taps unhappy face in SRL (-) item] in each case and -1 point for misses [Misses= child taps unhappy face in SRL (+) items] and false [False alarm= child taps happy face in SRL (-) item] alarms. This procedure should prevent distortions caused by guessing or systematic response bias (Coe, Waring, Hedges, \& Arther, 2012). The total score ranges from -24 (exclusively misses and false alarms) to +24 (exclusively hits and correct rejections).

\section{Age-appropriateness}

In consideration of preschoolers' lacking reading abilities, the scenarios and proposed solution strategies were presented orally by the test leaders. To improve understanding, children could follow the explanations by looking at coloured drawings. In contrast to Lockl et al. (2016), a dichotomous response format (happy vs. unhappy face) was ap-plied to prevent the error of central tendency. The protagonist and the scenarios are designed in a way that should foster self-identification with the cover story to enhance treatment motiva-tion.

\section{Test construction process}

Initially, the first version of the measurement tool to as-sess SRL in preschoolers was structured differently, since it consisted of a smaller number of problem scenarios with a higher number of corresponding items (two SRL (+) items and two SRL (-) items). The following SRL strategies were captured: planning, using prior knowledge, dealing with deflectors, self-efficacy, monitoring, breaks and self-motivation and reflection. The aim of the construction process was a preferably balanced measurement tool with a solid theoretical foundation. Consequently, the number of SRL (+) and SRL (-) items was balanced as well as the total number of items representing each learning strategy. The temporal dimen-sion of SRL was considered (c. Zimmerman, 2000). The relevant learning strategies were embedded in this structure and build on each other, leading towards an overarching goal.

Before the presented study, a pilot study was conducted with a smaller sample of $N=15$ preschoolers of two German kindergartens who agreed on request to participate. These children were between 5 and 6 years old. The analyses of the data of this pilot study led to the following modifications which resulted in the used, modified test tool: First, three SRL (+) items, which were used to capture the SRL strategies of planning, dealing with deflectors and reflection, showed ceiling effects. A further three items showed poor discriminatory power. These were constructed to measure the SRL strategies of planning (SRL (+) item) and monitoring (SRL (+) and SRL (-) item). Second, the data indicated that children were not able to keep the initial scenario in mind when four response alternatives

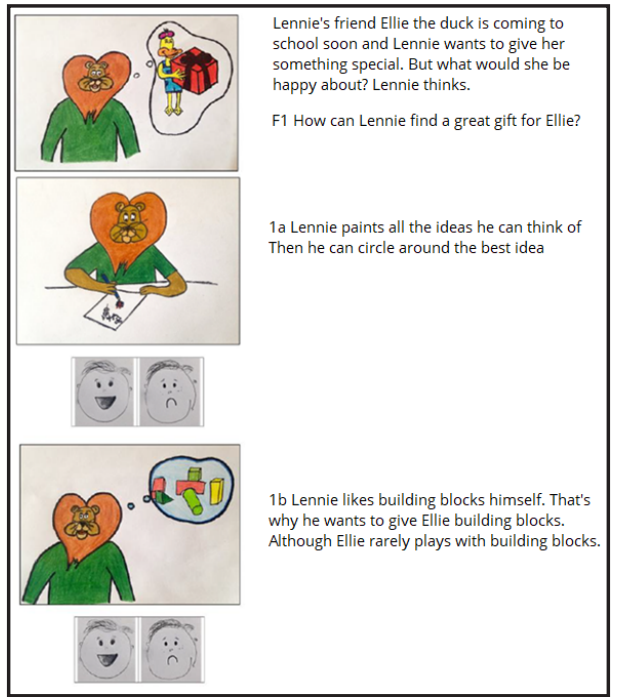


were presented. Consequently, the number of response alternatives was reduced from four to two responses (one SRL + and one SRL - for each scenario). Third, answering texts were shortened and a linguistic revision was made with the help of a team of experts consisting of educational scientists and psychologists, in order to ameliorate the understanding. As a consequence of the pilot study, changes at the structural and single item level were made and led to the final instrument (see section Cover story, structure of measurement tool and items).

\section{Synthesis}

In summary, different elements were useful to build the final SRL meas-ure tool presented in this study. First, Zimmerman's (2000) model of SRL served as theoretical base. Second, the adapted story used in Perels (2009) served as cover story. Third, the child-appropriate presentation of SRL problem scenarios and corresponding response was inspired by Lockl et al. (2016). Fourth, the test evaluation is based on the signal detection theory of Swets (1996). Fifth, the results of our pilot study influenced item selection, number of responses and linguistic elaboration of the final SRL measure tool.

\section{External rating-scale of self-regulated learning (SRL rating scale)}

The SRL rating scale is an external assessment of SRL in preschoolers, filled out by their kindergarten teachers as experts. On the one hand, the item pool consists of a selection of items used in two previous studies examining SRL in children, namely studies by Otto (2007) and Merget-Kullmann and Wende (2004). On the other hand, it consists of items from two established measurement tools: the Children's Independent Learning Development (CHILD 3-5) checklist (Whitebread et al., 2009) and the Child behavioural ratings scale (Rowley, 2015). Item selection is based on con-tent considerations and the results from item analysis of a former version of the SRL rating scale, used in Venitz \& Perels (2018). All items of the composed measurement tool were rated on a Four Point Likert scale that ranges from 1 (never) to 4 (always). The questionnaire, which is structurally related to the SRL measure tool for preschoolers, contains 35 items, which are grouped into eight subscales operationalizing SRL learning strategies. The structure and relia-bilities of the SRL rating scale are shown in Table 1.

Table 1. Structure and reliabilities of the SRL rating scale

\begin{tabular}{|c|c|c|c|}
\hline Phase & Scale & $\mathrm{N}$ & $\begin{array}{r}\text { Cronbach's } \\
\text { Alpha }\end{array}$ \\
\hline \multirow{4}{*}{$\begin{array}{l}\text { Forethought phase } \\
\text { (e.g. 'in a difficult } \\
\text { task, the child } \\
\text { considers exactly } \\
\text { how it wants to } \\
\text { proceed.') }\end{array}$} & $\begin{array}{l}\text { Definition of goals \& } \\
\text { planning }\end{array}$ & 7 & .87 \\
\hline & Using prior knowledge & 2 & .77 \\
\hline & $\begin{array}{l}\text { Planning \& } \\
\text { organisation }\end{array}$ & 3 & .62 \\
\hline & Self-efficacy & 7 & .85 \\
\hline \multirow{4}{*}{$\begin{array}{l}\text { Performance phase } \\
\text { (e.g. 'The child } \\
\text { can resist dis- } \\
\text { trac-tions.') }\end{array}$} & $\begin{array}{l}\text { Breaks \& self-moti- } \\
\text { vation }\end{array}$ & 1 & $--^{*}$ \\
\hline & Keeping up & 4 & .78 \\
\hline & $\begin{array}{l}\text { Dealing with deflec- } \\
\text { tors }\end{array}$ & 5 & .50 \\
\hline & Monitoring & 3 & .70 \\
\hline \multicolumn{4}{|l|}{$\begin{array}{l}\text { Self reflection } \\
\text { phase }\end{array}$} \\
\hline $\begin{array}{l}\text { (e.g. 'The child can } \\
\text { talk about how } \\
\text { something was } \\
\text { done or learned.') }\end{array}$ & Reflection & 3 & .73 \\
\hline Overall scale & Self-regulated learning & 35 & .78 \\
\hline
\end{tabular}

\section{Executive functioning (ToL Test)}

We used a modified version of the ToL Test (Shallice, 1982), a well-known and valid neuropsychological test of satisfactory to high reliability with $\alpha=.78$ (Tuche \& Lange, 2004), used to measure EF, in particular test takers' planning ability and problem solving ability. The version we used in this study was shortened from 20 to 10 items because the examined age cohort was of a younger age than the target group of the original ToL Test. One example problem and ten problems (or items) were administered. For each item, a stimulus card with a target configuration was presented to the child. Children were asked to rearrange three different-coloured balls on three bars in different sizes so that the target configuration turns out. The number of ball movements was predefined, so the child has to make a plan before starting the action. The range of total performance ranges from 0 to 10 points $(1=$ Problem solved correctly in compliance with the specified number of ball move-ments, $0=$ Problem not solved).

\section{Statistical Procedure}

The internal consistency of the SRL measure tool for preschoolers was estimated with the Kuder-Richardson formula which can be regarded as an antecedent of Cronbach's alpha and is used to deal with dichotomous data. Concurrent validity was estimated by correlating (a) an indicator of an external measurement tool of the domain of SRL; that is, scores of the SRL external rating scale, and (b) an indicator of a measurement tool of the related domain of EF that is also applied on the child level; that is, performance and planning time in the ToL Test.

\section{Results}

\section{Sample Test Results}

The descriptive data of the SRL variables and the EF variable are shown in Table 2. Data is based on the analytic sample of $N=164$

Table 2. Descriptive data of SRL variable and EF variable

\begin{tabular}{lrrr}
\hline & $M(S D)$ & Min & Max \\
\hline $\begin{array}{l}\text { SRL measure tool for pre- } \\
\text { Schoolers }\end{array}$ & $6.6(5.2)$ & -6 & 19 \\
\hline SRL rating scale & & & \\
\hline ToL Test $^{c}$ & $85.5(10.1)$ & 61 & 106 \\
\hline${ }^{{ }^{a}}$ measuring range: -24 to 24, ${ }^{b}$ measuring range: 35 to 140, cmeasuring range: 0 to 10
\end{tabular}

\section{Item Analysis}

Table 3 illustrates the descriptive item statistics, including item difficulty of the SRL measure tool for preschoolers. In eight SRL (+) items (1a, 3a, 4b, 6b, 7a, 9a, 10b,11a) ceiling effects $(P>80)$ were found, whereas one SRL $(-)$ item (11b) showed floor effect $(P<20)$. Therefore, those items were dropped for further analysis.

When analysing the discriminatory power of the fifteen remaining items, four SRL + items showed a low (negative) item-scale-correlations (2b: $r=-.09,5 a: r=-.14,8 b: r=-.16$, $12 \mathrm{~b}: r=-.15)$.

Both types of items - those items with ceiling/ground effects and those items with low discriminatory power - would impair the reliability and consequently the validity of the SRL measurement tool. In sum, all $12 \mathrm{SRL}(+)$ items and one SRL $(-)$ item were removed from further analysis. Consequently, further analyses are based exclusively on the remaining 11 SRL (-) items. Nevertheless, all SRL strategies are still captured by the measurement tool, which also means that 
items from all SRL phases (forethought phase, performance phase, reflection phase) were preserved.

\section{Reliability Analysis}

The internal consistency of the final SRL measurement tool for preschoolers (including 11 items) was $a=.72$. The corrected item-total correlations varied between $r_{i t}=.17$ and $r_{\text {it }}=.55$ (see table 3) with an average of $r_{i t}=.35$. The internal consistency of the three theoretically plausible subscales representing the three phases of learning (each comprising four items) was $a=.42$ for forethought phase of SRL, $a=.58$ for performance phase of SRL and $\alpha=.40$ for self-reflection phase of SRL.

\section{'Near Cross-Validation' Using an External Srl Measurement Tool}

The Pearson correlation coefficient between the total score of the SRL measurement tool for preschoolers and the SRL rating scale $(M=98.10, S D=17.29)$ was $r=.20$ and reached significance at the .05 level $(p=.03)$. Because of insufficient reliabilities of the assumed subscales (phases of learning) in the SRL measurement tool, further analysis on subscale level was not conducted. Based on theoretical assumptions, correlation coefficients between the single items of the SRL measure tool for preschoolers and the corresponding reliable subscales of the SRL rating scale were calculated and are shown in Table 5.

'Far Cross-Validation' Using an EF Measurement Tool Applied At Child-Level

The Pearson correlation coefficient between the total score of the SRL measurement tool for pre-schoolers and the performance in the ToL Test $(M=6.81, S D=1.90)$ was $r=.18(p=.018)$.

\section{Discussion}

The aim of this study was to initialize the development and evaluation of a direct, quantitative (online-) measurement tool of SRL for preschoolers by considering the cognitive and linguistic development status of children at this age. This topic has been subject to little research to date. For this reason, we intended to expand the repertoire of existing SRL method-ology for the preschool age ranges (Spörer \& Brunstein, 2006). The SRL measurement tool presented in this study is a time-efficient, child-friendly instrument that was developed for ap-plication in field settings such as kindergartens. The results reported in this paper indicate ini-tial empirical support for the psychometric quality of the instrument, yet may also especially indicate possibilities for optimization.

\section{The Reliability Analysis}

Statistical analysis indicated a satisfactory reliability of the overall scale of the SRL measurement tool for preschoolers after the initially constructed instrument had undergone some changes. Importantly, the SRL (-) items proved to be of appropriate item difficulty in contrast to the SRL (+) items, where many items suffered from ceiling effects. A possible explanation could be response biases in the form of acquiescence phenomena (Coe, Waring, Hedges \& Arther, 2012) which describes children's tendency to agree with the test leader or protagonist of a cover story. For instance, Cleveland, Quas, and Lyon (2016) demonstrated children's sensitivity for acquiescence in interviews at preschool age. Even though we intended to reduce distortions by adequate formulations of test instruction ('Do you think Lennie's idea is a good/bad idea or a bad/ good idea'? in varying order) we, presumably, could not counteract the sensitivity for response bias in this age group. Evaluating

Table 3. Descriptive item statistics and item difficulty

\begin{tabular}{|c|c|c|c|c|c|c|}
\hline Item & Phase & Learning strategy & Content & Mean & $S d$ & $P_{i}^{a}$ \\
\hline $1 a$ & & Using prior knowledge & SRL (+) & .76 & .66 & 88.0 \\
\hline $1 b$ & & & SRL (-) & .02 & 1 & 51.0 \\
\hline $2 a$ & & Planning & SRL (-) & -.56 & .83 & 22.0 \\
\hline $2 b$ & & & SRL (+) & .52 & .86 & 76.0 \\
\hline $3 a$ & & & $\mathrm{SRL}(+)$ & .81 & .60 & 90.5 \\
\hline $3 b$ & & & SRL (-) & .27 & .97 & 63.5 \\
\hline $4 a$ & & Self-efficacy & SRL (-) & .15 & .99 & 57.5 \\
\hline $4 b$ & & & SRL $(+)$ & .79 & .61 & 89.5 \\
\hline $5 a$ & & Breaks/self-motivation & SRL (+) & .58 & .82 & 79.0 \\
\hline $5 b$ & & & SRL (-) & -.53 & .85 & 23.5 \\
\hline $6 a$ & & Breaks/self-motivation & SRL (-) & .24 & .98 & 62.0 \\
\hline $6 b$ & & & SRL $(+)$ & .81 & .59 & 90.5 \\
\hline $7 a$ & & Breaks/self-motivation & SRL $(+)$ & .68 & .73 & 84.0 \\
\hline $7 b$ & & & SRL (-) & -.38 & .93 & 31.0 \\
\hline $8 a$ & & Dealing with deflectors & SRL (-) & -.19 & .99 & 40.5 \\
\hline $8 b$ & & & SRL $(+)$ & .59 & .81 & 79.5 \\
\hline $9 a$ & & Monitoring & SRL (+) & .75 & .67 & 87.5 \\
\hline $9 b$ & & & SRL (-) & -.03 & 1 & 48.5 \\
\hline $10 a$ & & Reflection & SRL (-) & -.43 & .91 & 28.5 \\
\hline $10 \mathrm{~b}$ & & & SRL (+) & .81 & .59 & 90.5 \\
\hline $11 \mathrm{a}$ & & Reflection & SRL (+) & .76 & .66 & 88.0 \\
\hline $11 b$ & & & SRL (-) & -.66 & .75 & 17.0 \\
\hline $12 \mathrm{a}$ & forethought phase & Attribution & SRL (-) & .37 & .93 & 68.5 \\
\hline $12 b$ & & & SRL $(+)$ & .51 & .86 & 75.5 \\
\hline
\end{tabular}

${ }^{a} P_{i}=\left(x_{i}-x_{\min } / x_{\max }-x_{\min }\right) * 100$ 
Table 4. Item total correlations of the 11 items considered in reliability analysis

\begin{tabular}{|c|c|c|}
\hline Item & Self-regulated learning strategy with wording item & $r_{i t}$ \\
\hline $1 \mathrm{~b}$ & $\begin{array}{l}\text { using prior knowledge SRL (-), 'Lennie likes building blocks himself. That's why he intends to give Ellie building } \\
\text { blocks. Although Ellie rarely plays with building blocks.' }\end{array}$ & .38 \\
\hline $2 a$ & planning SRL (-), 'Lennie says, "I'II get right to it. It's much faster without a craft book!' & .16 \\
\hline $3 b$ & $\begin{array}{l}\text { planning SRL (-), 'Lennie rashly takes everything out of the craft cupboard. It does not matter whether he needs all } \\
\text { those things.' }\end{array}$ & .41 \\
\hline $4 a$ & $\begin{array}{l}\text { self-efficacy SRL (-), 'Lennie thinks he's not even starting to make the school cone. He is not very good at cutting } \\
\text { out.' }\end{array}$ & .28 \\
\hline $5 b$ & breaks SRL (-), 'Lennie does not take a break. He's tired, but without a break it does not take so long.' & .30 \\
\hline $6 a$ & self-motivation SRL (-), 'Lennie says to himself, "I’m fed up! I just have to keep going."' & .39 \\
\hline $7 \mathrm{~b}$ & self-motivation SRL (-), 'Lennie could give crayons to Ellie. Then he does not have to continue tinkering.' & .38 \\
\hline $8 a$ & $\begin{array}{l}\text { dealing with deflectors SRL (-), 'Lennie says: “Let's go! I' m going to play along with you!" Playing football is more } \\
\text { fun than doing handicrafts.' }\end{array}$ & .54 \\
\hline $9 b$ & $\begin{array}{l}\text { monitoring SRL (-), 'Lennie tells himself: "I don't know if I do it exactly as it is said in the craft book." It takes far too } \\
\text { long to look it up in the craft book!' }\end{array}$ & .33 \\
\hline $10 a$ & $\begin{array}{l}\text { reflection SRL (-), 'Lennie does not check whether his school cone looks correct. He puts the school cone aside } \\
\text { quickly and walks away to play.' }\end{array}$ & .40 \\
\hline $12 a$ & causal attribution SRL (-), 'Lennie believes he is the reason - he's just not good at doing handicrafts.' & .34 \\
\hline
\end{tabular}

Table 5. Correlation coefficients between subscale of the SRL rating scale and single items of the developed measure tool

\begin{tabular}{llr}
\hline SRL rating scale & SRL measure tool for preschoolers & Validation \\
\hline Subscale & Content of item & $\begin{array}{r}\text { Correlation } \\
\text { Coefficient }\end{array}$ \\
\hline Using prior knowledge & 1b Lennie wants to give Ellie building blocks although she rarely plays with those. & $.24^{* *}$ \\
\hline Definition of goals \& planning & 3b lt's much faster without a craft book. & $.28^{* *}$ \\
\hline Planning \& organisation & 2a Lennie takes all materials, no matter if they are useful. & .02 \\
\hline Self-efficacy & 4a Lennie refuses to start with work because he is not good at cutting out. & -.02 \\
\hline Breaks and self-motivation & 5b Lennie does not take a break because it would take too long. & -.09 \\
\hline Keeping up & 6a Lennie ignores that he loses interest in doing handicrafts. & $.20^{*}$ \\
\hline Keeping up & 7b Lennie thinks about another kind of present for his friend. & .10 \\
\hline Dealing with deflectors & 8a While working, Lennie decides to play football. &.$--{ }^{*}$ \\
\hline Monitoring & 9b Lennie does not want to check if he proceeds correctly. & .06 \\
\hline Reflection & 10a Lennie does not check the result of his work. & $.21^{*}$ \\
\hline$--{ }^{*}$ & 12a Lennie blames himself. & \\
\hline
\end{tabular}

${ }^{* *} p=.001,{ }^{*} p<.05,{ }^{a}$ subscale not reliable (see section 'measures'), ${ }^{b}$ no corresponding subscale in SRL rating

items as 'highly beneficial' (or 'good idea') could explain the ceiling effects in specifically those SRL (+) items, where "highly beneficial' is the correct answer and consequently rated as a hit. Potentially, the SRL (-) items, which showed a good item difficulty, were able to counteract response biases and, additionally, made greater demands on children - they need to inhibit an automatic response tendency such as 'agreeing'. Probably, SRL (-) items represent a type of item that is more differentiating and appropriate to explore SRL on the child level with the kind of measure tool we used.

Contrary to our assumptions, the reliability of subscales, also on the time axis based on Zimmerman's (2000) process model of SRL (forethought phase, performance phase, self reflection phase), was limited in our preschool sample. The specific developmental status of the exam-ined age cohort may serve as an explanation. To be precise, there are two possible explanations as to why the application of our measurement tool might have failed to yield the expected subscale structure: (a) The sensitive period of preschool age is characterized by critical cognitive maturation processes that enable individuals to regulate their thinking and behavior (Montroy et al., 2016; Zelazo, 2015). Potentially, our tested children might, however, have just started to apply particular learning strategies which may have crossed the sequential order as assumed in the SRL process model. The integration into a holistic learning process could then evolve at a later point in time. Consequently, the process model of
SRL (Zimmerman, 2000) would not be as easily applicable as in other age groups such as, for example, students (Leidinger \& Perels, 2012) or university students (Dörrenbächer \& Perels, 2016; Schmitz, Klug, \& Schmidt, 2011). (b) The assumption that the use of intuitive learning strategies does not fit the process model (Zimmerman, 2000) does not necessarily render preschoolers unable to integrate the learning strategies into a holistic process. Rather, they may be in need of special support through programmes with a focus on SRL. Training studies in combination with multi-methodological measurement of change are essential to test this hypothesis and may shed more light on the developmental progress of SRL in preschoolers.

\section{The Validity Analysis Using 'Near and Far Cross Validation'}

Results of the validity analysis, using two established instruments with good psychometric quality as criterions, suggest that the newly constructed tool as a whole seems to measure SRL-like abilities: Both the total scores of a structurally similar external measure and the structurally dissimilar EF measure show significant correlations with the newly developed test. Additionally, analyses on the single item level gathered more information on the validity of our instrument: In sum, four items (1b /using prior knowledge, $3 \mathrm{~b} /$ planning, $6 \mathrm{a} /$ self-motivation and $10 \mathrm{a} /$ reflection) showed significant correlations with the corresponding sub-scales of the external rating scale. This demonstrates that the at- 
tempt to cover different SRL-relevant learning strategies may have been successful and supports the idea that the particular SRL strategies - possibly without support - evolve in a more independent manner than as-sumed in the SRL process model (Zimmerman, 2000). In this context, it might be of interest to examine particular learning strategies more deeply by using a larger item pool with the aim to (a) replicate our findings that certain SRL strategies (using prior knowledge, planning, self-motivation and reflection) are indeed already measurable on the child level and (b) ameliorate problem scenarios and corresponding items to operationalize the particular SRL strategies of our SRL measurement tool for preschoolers.

\section{Limitations and Outlook}

Naturally, there are limiting factors and unanswered questions regarding this study. First, the test results on the child level are based on only one measurement point. Consequently, the results possibly represent a 'snapshot' which may be influenced by the way children felt on the day of testing as well as outside factors such as, for example, interruptions while playing for the purpose of testing. Contrary to the direct measure of SRL, the indirect measure via external ratings by the kindergarten teachers is based on many observation moments in the every-day life of kindergarten. In future research, assessing the constructs of interest on at least two occasions would be useful. Second, properties of the kindergarten teachers limit the results: (a) the external ratings are subject to the response behaviour of the respective kindergarten teacher which filled out the questionnaire; (b) even though kindergarten teachers were introduced to the topic of SRL in the run-up to the filling out of the questionnaire, their knowledge after this instruction was not systematically examined, so a different degree of expertise and sensitivity to the detection of SRL abilities is conceivable; and (c) the time period during which the kindergarten teachers attended the respective child was not recorded, but could assumedly have influenced the validity of the rating. Third, the age range of the examined preschoolers is approximately two years because the status of 'preschoolers' was chosen as the inclusion criterion instead of the numerical age. This procedure may have resulted in a loss of information concerning interindividual developmental differences and corresponding SRL abilities in the wide age range. Therefore, future research in the field of SRL in preschoolers should restrict the age range.

\section{Summary and Practical Implications}

In summary, the present findings indicate that it seems both plausible and possible to assess SRL online at the child level in an objective and quantitative manner. Further research is needed (a) to make valid statements about the fit of the underlying theoretical model that was considered in our test construction process, (b) to justify an appropriate selection of SRL strat-egies that are already measurable at preschool age (intuitively or after SRL intervention programs) via direct measurement, and (c) to optimize test instructions and item construction with regard to difficulties that may arise from the particular response behaviour in preschool children.

The further development of the SRL test tools is important for the realisation of adapted educational tasks in kindergartens which do not dispose of a structured, well-defined curriculum for the preschool year (as it is the case in Germany). A preferably simple and standardized applicability of such a tool is important to allow a) the execution by external trainers visiting kindergarten in the context of intervention programs as well as b) the execution by kindergarten teachers. An uncomplicated application with no need of special equipment and less spatial conditions (only a quiet room to test children one by one) should allow for usage in kindergarten setting. Direct SRL assessment tools of high psychometric quality are a necessary precondition to develop and empirically verify programmes aiming to promote SRL in intervention settings (Hoyle \& Dent, 2018). In this context, the usage of an SRL test tool as a perfor- mance measure before and after an SRL interventions is thinkable. Furthermore, a SRL test tool allows to track progress in SRL through repeated measurement (formative assessment).

Finally, the overarching goal to do research on early SRL assessment in preschool children is to facilitate the transition from kindergarten to primary school. The assessment and promotion of basic skill such SRL represents an important pillar due to the documented association between SRL with both academic and life success (e.g. Eisenberg et al., 2005; McClelland et al., 2013).

\section{Funding}

This study was funded by Deutsche Forschungsgemeinschaft (DFG) (grant number PE 1176/13-2).

\section{Acknowledgements}

We thank Efsevia Kapsali and Nathalie Zetzmann for their help in the construction process. Furthermore, we thank Lisa Dörr and the whole team of student assistants for their help in data collection. Additionally, we want to thank all preschoolers and their parents as well as all kin-dergarten managements for their participation.

\section{References}

Ackerman, D. J., \& Friedman-Krauss, A. H. (2017). Preschoolers' executive function: Importance, contributors, research needs and assessment options. ETS Research Report Series, 1, 1-24.

Barkley, R. A. (2001). The executive functions and self-regulation : An evolutionary neuropsychological perspective. Neuropsychology Review, 11(1), 1-29.

Blaye, A., \& Chevalier, N. (2011). The role of goal representation in preschoolers' flexibility and inhibition. Journal of Experimental Child Psychology, 108(3), 469-483.

Boekarts, M. (1999). Self-regulated learning: Where we are today. International Journal of Educational Research, 31(6), 445-457.

Bronson, M. B. (1994). The usefulness of an observational measure of young children's social and mastery behaviors in early childhood classrooms. Early Childhood Research Quarterly, 9(1), 19-43.

Bronson, M. B. (2000). Self-regulation in early childhood: Nature and nurture. New York: Guilford Press.

Brunstein, J. C., \& Spörer, N. (2010). Selbstgesteuertes Lernen. In D. H. Rost (Ed.), Handwörterbuch pädagogische Psychologie (pp. 751-759). Weinheim, Basel: Beltz.

Bryce, D., \& Whitebread, D. (2012). The development of metacognitive skills: Evidence from observational analysis of young children's behavior during problem-solving. Metacognition and Learning, 7(3), 197-217.

Brydges, C. R., Reid, C. L., Fox, A. M., \& Anderson, M. (2012). A unitary executive function predicts intelligence in children. Intelligence, 40(5), 458-469.

Byrd, D. L., Van Der Veen, T. K., McNamara, J. P. H., \& Berg, W. K. (2004). Preschoolers Don't Practice What They Preach: Preschoolers' Planning Performances With Manual and Spoken Response Requirements. Journal of Cognition and Development, 5(4), 427-449.

Carlson, S. M. (2005). Developmentally sensitive measures of executive function in preschool children. Developmental Neuropsychology, 28(2), 595-616. 
Cleveland, K. C., Quas, J. A., \& Lyon, T. D. (2016). Valence, implicated actor, and children's acquiescence to false suggestions. Journal of Applied Developmental Psychology, 43, 1-7.

Coe, R.; Waring, M.; Hedges L.V.; Arther, J. (2012). Research Methods \& Methodologies in education. London: SAGE Publications.

Dörrenbächer, L., \& Perels, F. (2016). More is more? Evaluation of interventions to foster self-regulated learning in college. International Journal of Educational Research, 78, 50-65.

Dörrenbächer, L., Russer, L., \& Perels, F. (2018). Selbstregulationstraining für Studierende: Sind quantifizierte qualitative Lerntagebuchdaten zur Wirksamkeitsüberprüfung geeignet? Zeitschrift Für Hochschulforschung, 1, 40-56.

Durrett, M. E. (1959). The relationship of early infant regulation and later behavior in play interviews. Child Development, 30(2), 211-216.

Eisenberg, N., Sadovsky, A., Spinrad, T. L., Fabes, R. A., Losoya, S. H., Valiente, C., ... \& Shepard, S. A. (2005). The relations of problem behavior status to children's negative emotionality, effortful control, and impulsivity: Concurrent relations and prediction of change. Developmental Psychology, 41(1), 193-211.

Erb, C. D., Moher, J., Song, J.-H., \& Sobel, D. M. (2017). Cognitive control in action: Tracking the dynamics of rule switching in 5- to 8-year-olds and adults. Cognition, $164,163-173$.

Fadlelmula, F. K., Cakiroglu, E., \& Sungur, S. (2015). Developing a Structural Model on the Relationship among Motivational Beliefs, Self-Regulated Learning Strategies, and Achievement in Mathematics. International Journal of Science and Mathematics Education, 13(6), 1355-1375.

Gamannossi, B. A., \& Pinto, G. (2014). Theory of mind and language of mind in narratives: Developmental trends from kindergarten to primary school. First Language, 34, 262-272.

Gaskins, I. W., Satlow, E., Pressley, M., \& Meltzer, L. (2007). Executive Control of Reading Comprehension in the Elementary School. In L. Meltzer (Ed.), Executive function in education: From theory to practice (pp. 194215). New York: The Guilford Press.

Goodman, R. (1997). The Strengths and Difficulties Questionnaire: a research note. Journal of Child Psychology and Psychiatry, 38(5), 581-586.

Hembacher, E., \& Ghetti, S. (2014). Don't Look at My Answer: Subjective Uncertainty Underlies Preschoolers' Exclusion of Their Least Accurate Memories. Psychological Science, 25(9), 1768-1776.

Hendry, A., Jones, E. J. H., \& Charman, T. (2016). Executive function in the first three years of life: Precursors, predictors and patterns. Developmental Review, 42, $1-33$.

Hofmann, W., Schmeichel, B. J., \& Baddeley, A. D. (2012). Executive functions and self-regulation. Trends in Cognitive Sciences, 16(3), 174-180.

Howse, R. B., Lange, G., Farran, D. C., \& Boyles, C. D. (2003). Motivation and self-regulation as predictors of achievement in economically disadvantaged young children. The Journal of Experimental Education, 71(2), 151-174.
Hoyle, R. H., \& Dent, A. L. (2018). Developmental trajectories of skills and abilities relevant for self-regulation of learning and performance. In D. H. Schunk \& J. A. Greene (Eds.), Handbook of Self-regulation of Learning and Performance (pp. 49-63). New York: Taylor \& Francis.

Jurado, M. B., \& Rosselli, M. (2007). The elusive nature of executive functions: A review of our current understanding. Neuropsychology Review, 17(3), 213-233. https://doi.org/10.1007/s11065-007-9040-z

Kochanska, G., Coy, K. C., \& Murray, K. T. (2001). The Development of Self-Regulation in the First Four Years of Life. Child Development, 72(4), 1091-1111.

Landmann, M., Perels, F., Otto, B., Schnick-Vollmer, K., \& Schmitz, B. (2009). Selbstregulation und selbstreguliertes Lernen. In E. Wild \& J. Möller (Eds.), Pädagogische Psychologie (pp. 45-62). Berlin Heidelberg: Springer.

Leidinger, M., \& Perels, F. (2012). Training Self-Regulated Learning in the Classroom: Development and Evaluation of Learning Materials to Train Self-Regulated Learning during Regular Mathematics Lessons at Primary School. Education Research International, 2012, 1-14. https://doi.org/10.1155/2012/735790

Lewis, F. C., Reeve, R. A., Kelly, S. P., \& Johnson, K. A. (2017). Evidence of substantial development of inhibitory control and sustained attention between 6 and 8 years of age on an unpredictable Go/No-Go task. Journal of Experimental Child Psychology, 157, 6680. https://doi.org/10.1016/j.jecp.2016.12.008

Lockl, K., Händel, M., Haberkorn, K., \& Weinert, S. (2016). Metacognitive Knowledge in Young Children: Development of a new test procedure for first graders. In H. P. Blossfeld, J. von Maurice, M. Bayer, \& J. Skopek (Eds.), Methodological Issues of Longitudinal Surveys: The Example of the National Educational Panel Study (pp. 465-485). Wiesbaden: Springer.

Lockl, K., \& Schneider, W. (2007). Knowledge about the mind: Links between theory of mind and later metamemory. Child Development, 78(1), 148-167. https://doi. org/10.1111/j.1467-8624.2007.00990.x

Maylor, E. A., \& Logie, R. H. (2010). A large-scale comparison of prospective and retrospective memory development from childhood to middle age. Quarterly Journal of Experimental Psychology, 63(3), 442-451. https:// doi.org/10.1080/17470210903469872

McClelland, M. M., Acock, A. C., Piccinin, A., Rhea, S. A., \& Stallings, M. C. (2013). Relations between preschool attention span-persistence and age 25 educational outcomes. Early Childhood Research Quarterly, 28(2), 314-324. https://doi.org/10.1016/j. ecresq.2012.07.008

McClelland, M. M., Morrison, F. J., \& Holmes, D. L. (2000). Children At Risk for Early Academic Problems: The Role of Learning-Related Social Skills. Early Childhood Research Quarterly, 15(3), 307-329. http://doi. org/10.1016/S0885-2006(00)00069-7

Mega, C., Ronconi, L., \& De Beni, R. (2014). What makes a good student? How emotions, self-regulated learning, and motivation contribute to academic achievement. Journal of Educational Psychology, 106(1), 121131. 
Merget-Kullmann, M., \& Wende, M. (2004). Konzeption, Durchführung und Evaluation eines Erzieherinnentrainings zum Thema "Lernen lernen mit Vorschulkindern." unpublished diploma thesis, Technische Universität Darmstadt.

Miyake, A., Friedman, N. P., Emerson, M. J., Witzki, A. H., Howerter, A., \& Wager, T. D. (2000). The Unity and Diversity of Executive Functions and Their Contributions to Complex "Frontal Lobe" Tasks: A Latent Variable Analysis. Cognitive Psychology, 41(1), 49-100. https://doi. org/10.1006/cogp.1999.0734

Montroy, J. J., Bowles, R. P., Skibbe, L. E., Mcclelland, M. M., \& Morrison, F. J. (2016). The Development of Self-Regulation Across Early Childhood. Developmental Psychology, 52(11), 1744-1762. https://doi.org/10.1037/ dev0000159

Otto, B. (2007). SELVES: Schüler-, Eltern- und Lehrertraining zur Vermittlung effektiver Selbstregulation. Berlin: Logos Verlag Berlin $\mathrm{GmbH}$.

Paris, A. H., \& Paris, S. G. (2003). Assessing narrative comprehension in young children. Reading Research Quarterly, 38(1), 36-76. https://doi.org/10.1598/RRQ.38.1.3

Perels, F. (2009). Mit Kindern lernen lernen: selbstreguliertes Lernen im Kindergarten anleiten. Göttingen: Vandenhoeck \& Ruprecht.

Perels, F., Merget-Kullmann, M., Wende, M., Schmitz, B., \& Buchbinder, C. (2009). Improving self-regulated learning of preschool children: Evaluation of training for kindergarten teachers. British Journal of Educational Psychology, 79(2), 311-327. https://doi. org/10.1348/000709908X322875

Perry, N. E., Hutchinson, L. R., Yee, N., \& Määttä, E. (2018). Advances in understanding young children's self-regulation of learning. In D. H. Schunck \& J. A. Greene (Eds.), Handbook of self-regulation of learning and performance (pp. 457-472). New York: Routledge.

Ponitz, C. C., McClelland, M. M., Matthews, J. S., \& Morrison, F. J. (2009). A Structured Observation of Behavioral Self-Regulation and its Contribution to Kindergarten Outcomes. Developmental Psychology, 45(3), 605-619. https://doi.org/10.1037/a0015365

Raizner, R. D., Song, J., \& Levin, H. S. (2002). Raising the ceiling: The Tower of London-Extended Version. Developmental Neuropsychology, 21(1), 1-14.

Rowley, B. A. (2015). Kindergarten assessment: Analysis of the Child Behavioral Rating Scale (CBRS). Eugene: University of Oregon.

Schmitz, B., \& Schmidt, M. (2011). Assessing self-regulated learning using diary measures with university students. In B. J. Zimmerman \& D. H. Schunk (Eds.), Handbook of self-regulation of Learning and Performance ( $\mathrm{pp}$. 251-266). New York: NY: Routledge.

Schneider, W., \& Büttner, G. (2008). Entwicklung des Gedächtnisses bei Kindern und Jugendlichen. In L. Montada \& R. Oerter (Eds.), Entwicklungspsychologie (6th ed., pp. 480-501). Weinheim: Beltz.

Schnell, K., Ringeisen, T., Raufelder, D., \& Rohrmann, S. (2015). The impact of adolescents' self-efficacy and self-regulated goal attainment processes on school performance - Do gender and test anxiety matter? Learning and Individual Differences, 38, 90-98. https://doi. org/10.1016/j.lindif.2014.12.008
Shallice, T. (1982). Specific impairments of planning. Philosophical Transactions of the Royal Society of London, 298(1089), 199-209.

Shaul, S., \& Schwartz, M. (2014). The role of the executive functions in school readiness among preschool-age children. Reading and Writing, 27(4), 749-768.

Shing, Y. L., Lindenberger, U., Diamond, A., Li, S., \& Davidson, M. C. (2010). Memory maintenance and inhibitory control differentiate from early childhood to adolescence. Developmental Neuropsychology, 35(6), 679-697. https://doi.org/10.1080/87565641.2010.508546

Spörer, N., \& Brunstein, J. C. (2006). Erfassung selbstregulierten Lernens mit Selbstberichtsverfahren: Ein Überblick zum Stand der Forschung. Zeitschrift Für Pädagogische Psychologie, 20(3), 147-160.

Stephenson, K. M., \& Hanley, G. P. (2010). Preschoolers' Compliance With Simple Instructions: A Descriptive and Experimental Evaluation. Journal of Applied Behavior Analysis, 43(2), 229-247. https://doi.org/10.1901/ jaba.2010.43-229

Swets, J. A. (1996). Singal detection theory and ROC analysis in psychology and diagnostics: collected papers. Mahwah, N.J.: L.Erlbaum Associates.

Tabuenca, B., Kalz, M., Drachsler, H., \& Specht, M. (2015). Time will tell: The role of mobile learning analytics in self-regulated learning. Computers and Education, 89, 53-74. https://doi.org/10.1016/j.compedu.2015.08.004

Tompkins, V., Guo, Y., \& Justice, L. M. (2013). Inference generation, story comprehension, and language skills in the preschool years. Reading and Writing, 26(3), 403-429. https://doi.org/10.1007/s11145-012-9374-7

Tucha, O.; Lange, K. W. (2004). Turm von London - Deutsche Version TL-D. Göttingen: Hogrefe.

Van Den Broek, P., Kendeou, P., Lousberg, S., \& Visser, G. (2011). Preparing for reading comprehension: Fostering text comprehension skills in preschool and early elementary school children. International Electronic Journal of Elementary Education, 4(1), 259-268.

Venitz, L., \& Perels, F. (2018). Promoting self-regulated learning of preschoolers through indirect intervention: a two-level approach. Early Child Development and Care, $1-14$

Whitebread, D., Coltman, P., Pasternak, D. P., Sangster, C., Grau, V., Bingham, S., ... \& Demetriou, D. (2009). The development of two observational tools for assessing metacognition and self-regulated learning in young children. Metacognition and Learning, 4(1), 63-85. https://doi.org/10.1007/s11409-008-9033-1

Winne, P. H., \& Perry, N. E. (2005). Measuring Self-Regulated Learning. In M. Boekarts, P. Pintrich, \& M. Zeidner (Eds.), Handbook of self-regulation (pp. 531-599). San Diego: Acamedic Press.

Zelazo, P. D. (2015). Executive function: Reflection, iterative reprocessing, complexity, and the developing brain. Developmental Review, 38, 55-68. https://doi. org/10.1016/j.dr.2015.07.001

Zimmerman, B. J. (2000). Attaining self-regulation: A social cognitive perspective. In M. Boekarts, P. R. Pintrich, \& M. Zeidner (Eds.), Handbook of self regulation (pp. 13-41). San Diego: Acamedic Press. 


\section{Appendix A}

Example problem scenarios of the SRL measure tool for preschoolers (performance phase and self-reflection phase)

An example problem scenario for the learning strategy 'breaks and self-motivation' (perfor-mance phase of SRL, Figure A1) and an example scenario for the learning strategy 'reflection' (self-reflection phase of SRL, Figure A2) are listed below.
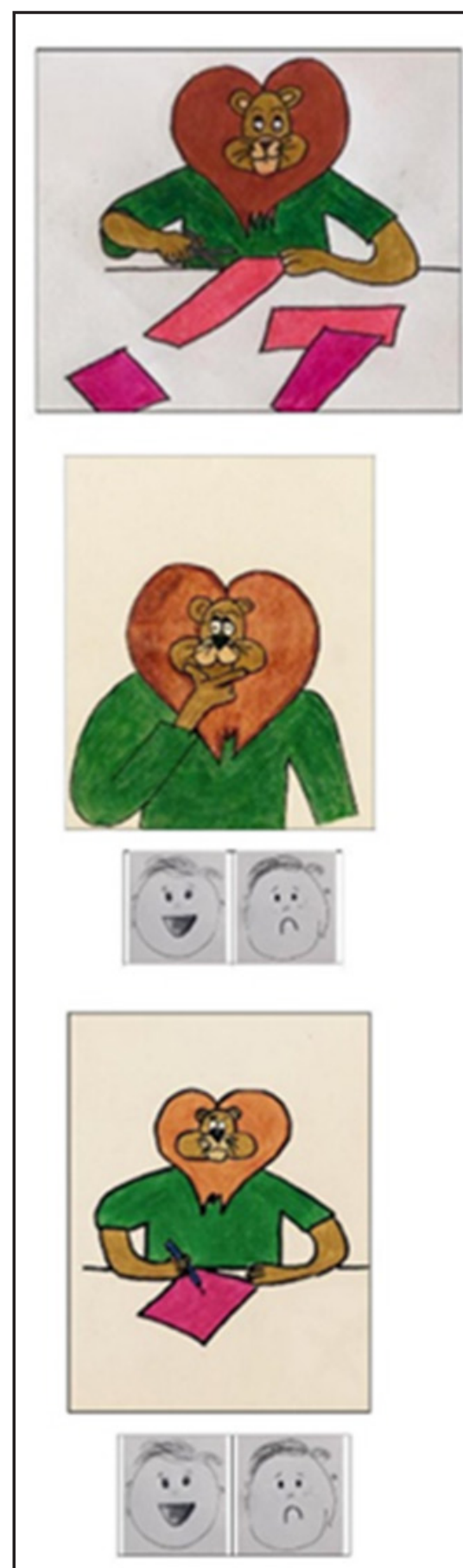

Lennie sits down at the craft table and makes the school cone.

But phew, that takes a long time!

F5 How can Lennie manage to finish the school cone?

5a Lennie takes a little break and takes a deep breath. Then he continues thinking.

5b Lennie does not take a break. He's tired, but without a break it does not take so long

Figure A1. Example problem scenario (F5) with corresponding SRL (+) item (5a), SRL (-) item (5b) in dichotomous response format (happy vs. unhappy face) 


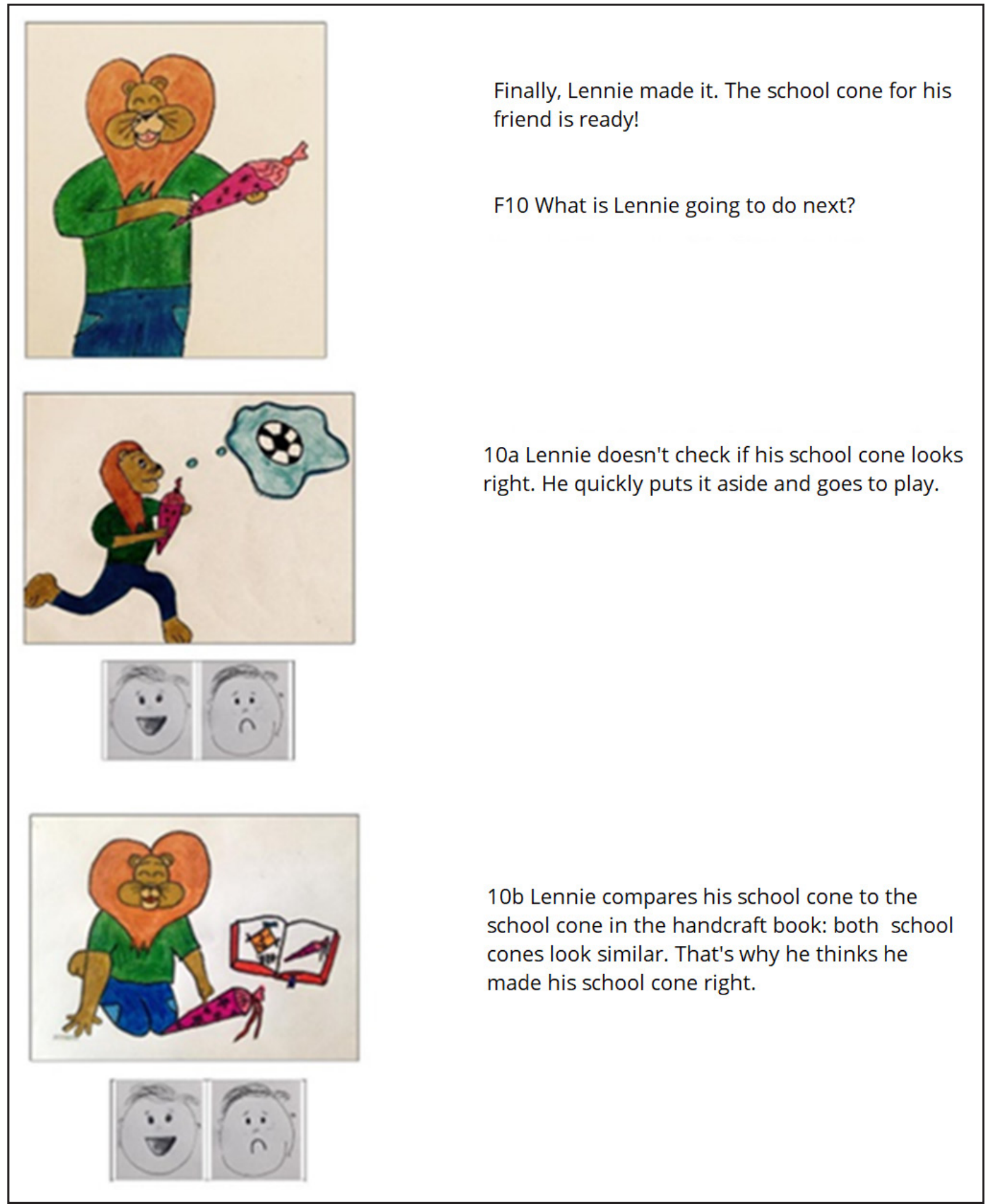

Figure A1. Example problem scenario (F5) with corresponding SRL (+) item (5a), SRL (-) item (5b) in dichotomous response format (happy vs. unhappy face) 